\title{
Escala Multidimensional de Preconceito Sexual: Propriedades Psicométricas para o Contexto Brasileiro
}

\author{
Leogildo Alves Freires ${ }^{1}$ \\ ${ }^{1}$ Universidade Federal de Alagoas, AL, Brasil. \\ Gleidson Diego Lopes Loureto ${ }^{2}$ \\ ${ }^{2}$ Universidade Federal da Paraíba, PB, Brasil. \\ Luis Augusto de Carvalho Mendes ${ }^{4}$ \\ ${ }^{4}$ Faculdade Maurício de Nassau, PB, Brasil.
}

\author{
Alessandro Teixeira Rezende ${ }^{2}$ \\ ${ }^{2}$ Universidade Federal da Paraíba, PB, Brasil. \\ Walberto Silva dos Santos ${ }^{3}$ \\ ${ }^{3}$ Universidade Federal do Ceará, CE, Brasil. \\ Valdiney Veloso Gouveia ${ }^{2}$ \\ ${ }^{2}$ Universidade Federal da Paraíba, PB, Brasil.
}

Resumo: Este artigo objetivou adaptar ao contexto brasileiro a Escala Multidimensional de Preconceito Sexual (EMPS), reunindo evidências de sua adequação psicométrica. Dois estudos foram realizados. O Estudo 1 considerou 223 estudantes universitários $\left(M_{\text {idade }}=22,5 ; 62,8 \%\right.$ mulheres), os quais responderam a EMPS e perguntas demográficas. A análise de componentes principais revelou uma estrutura pentafatorial [Heterossexismo $(\alpha=0,97)$,Aversão a homossexuais $(\alpha=0,94)$, Crenças positivas frente a homossexuais $(\alpha=0,89)$, Resistência à Heteronormatividade $(\alpha=0,91)$ e Negação da Discriminação $(\alpha=0,49)$ ]. No Estudo 2 participaram 261 pessoas da população geral ( $\mathrm{M}_{\text {idade }}=30,0 ; 61,7 \%$ mulheres), as quais responderam os mesmos instrumentos do estudo anterior. A análise fatorial confirmatória, considerando parcelas de itens, corroborou a estrutura pentafatorial (por exemplo, AGFI $=0,93$ e RMSEA $=0,05$ ). Concluiu-se que a EMPS é psicometricamente adequada, podendo ser utilizada em estudos futuros a fim de conhecer o preconceito sexual e seus correlatos.

Palavras-chave: Preconceito, Sexual, Escala, Brasil, Validade.

\section{Multidimensional Scale of Sexual Prejudice: Psychometric Properties for the Brazilian Context}

\begin{abstract}
This paper aimed to adapt the Multidimensional Scale of Sexual Prejudice (MSSP) to the Brazilian context, gathering evidence of its psychometric adequacy. Two studies were conducted. Study 1 participants were 223 undergraduate students $\left(M_{\text {age }}=22.5\right.$; $62.8 \%$ women $)$, who answered the MSSP and demographic questions. Principal components analysis indicated a five-factor structure [Heterosexist $(\alpha=0.97)$, Aversion to homosexuals $(\alpha=0.94)$, Positive beliefs towards homosexuals $(\alpha=0.89)$, Resistance to heteronormative $(\alpha=0.91)$, and Denial of discrimination $(\alpha=0.49)$ ]. Study 2 considered 261 people from the general population $\left(\mathrm{M}_{\text {age }}=\right.$ $30.0 ; 61.7 \%$ women), who answered the same instruments of the previous study. A confirmatory factor analysis, considering item parcels, corroborated the five-factor structure (e.g., AGFI = 0.93 , and RMSEA $=0.05$ ). In conclusion, the MSSP is a psychometrically adequate measure, and thus it can be used in future studies aiming to know the sexual prejudice and its correlates.
\end{abstract}

Keywords: Prejudice, Sexual, Scale, Brazil, Validity. 


\title{
Escala Multidimensional de Prejuicio Sexual (EMPS): Propiedades Psicométricas para el Contexto Brasileño
}

\begin{abstract}
Resumen: Este artículo ha tenido como objeto adaptar la Escala Multidimensional de Prejuicio Sexual (EMPS) al contexto brasileño, reuniendo evidencias de su adecuación psicométrica. Dos estudios han sido realizados. El Estudio 1 ha considerado 223 estudiantes universitarios $\left(\mathrm{M}_{\text {edad }}=22,5 ; 62,8 \%\right.$ mujeres $)$ que han contestado la EMPS y preguntas demográficas. El análisis de componentes principales demostró una estructura de cinco factores [Heterosexismo $(\alpha=0,97)$, Aversión a los homosexuales $(\alpha=0,94)$, Creencias positivas hacia a los homosexuales $(\alpha=0,89)$, Resistencia a la Heteronormatividad $(\alpha=0,91)$ y Negación de la Discriminación $(\alpha=0,49)$ ]. El Estudio 2 ha reunido 261 personas de la población general $\left(\mathrm{M}_{\text {edad }}=30,0 ; 61,7 \%\right.$ mujeres), que han contestado a los mismos instrumentos del estudio anterior. El análisis factorial confirmatorio, considerando parcelas de ítems, corroboró la estructura de cinco factores (por ejemplo, AGFI = 0,93 y RMSEA $=0,05$ ). Se ha concluido que la EMPS es una medida psicométricamente adecuada, pudiendo ser empleada en estudios futuros con el fin de conocer el prejuicio sexual, sus antecedentes y consecuentes.
\end{abstract}

Palabras clave: Prejuicio Sexual, Escala, Brasil, Validez.

O termo "homofobia", cunhado por George Weinberg na década de 1960 e difundido em 1972 no livro Society and the Healthy Homosexual, do mesmo autor, teve relevância capital para o estudo e a discussão dessa temática no meio científico, pois produziu modificação substancial das concepções a respeito e ajudou a popularizar a crença de que se tratava de um fenômeno social, merecedor de atenção e análise no meio científico. Além do mais, tornou-se um elemento importante para o ativismo LGBT+ e seus defensores, pois a partir de tal termo, o foco foi direcionado a quem discriminava pessoas com orientação homossexual, por exemplo (Herek, 2015).

Desde então, o termo homofobia passou a ser empregado como sinônimo de atitudes e comportamentos ofensivos frente a gays e lésbicas (Cerqueira-Santos, Nunes, \& Silveira, 2017). Apesar de popularizado e associado às atitudes negativas e aspectos emocionais presentes na relação heterossexual-homossexual, atualmente tem sido considerado uma denominação insatisfatória por parte de pesquisadores da área (Herek, 2015; Herek, \& McLemore, 2013). Tal fato, deve-se, fundamentalmente, a ênfase em atitudes extremas de apreensão psicológica, o que minimiza outras formas de hostilidade (por exemplo, violência, assassinato) e o contexto social de produção deste fenômeno (Chandra, Copen, \&, Mosher, 2013). Ademais, o termo tem sido empregado não como uma fobia propriamente dita, mas como uma hostilidade direcionada a homossexuais, uma vez que o componente emocional da fobia é a ansiedade, mas, no caso da homofobia, se destacam a raiva e o nojo frente a homossexuais (Herek, \& McLemore, 2013).

Nesse contexto, alguns pesquisadores têm sugerido o conceito de preconceito sexual (Herek, 2015; Herek, \& McLemore, 2013), visando superar as restrições e críticas que o termo homofobia tem recebido (Whitley, \& Kite, 2016). Segundo Herek (2000), o preconceito sexual pode ser definido como uma atitude negativa em direção a um indivíduo, baseado em fatores como a sua atração e orientação sexual. Em outras palavras, uma pessoa é vítima de discriminação social por não estar em conformidade com a norma cisheterossexista de determinada cultura, e não por medo do contato ou pavor, que suscita a homofobia (Herek, 2015). Portanto, o preconceito sexual constitui-se como uma nomenclatura mais apropriada para descrever as atitudes negativas das pessoas em relação a comportamentos de indivíduos com orientação não heterossexual (Whitley, \& Kite, 2016).

Além do mais, o preconceito sexual se manifesta a partir de diferentes facetas, englobando a tríade de componentes cognitivo, afetivo e comportamental, evidente em estudos sobre atitudes preconceituosas (Santos, Gouveia, Navas, Pimentel, \& Gusmão, 2006). Porém, a concepção do preconceito sexual vai além, 
incorporando componentes sociais (culturais e políticos) relacionados aos estigmas em torno do preconceito, tais como as ideologias construídas com base em padrões de opressão institucionalizada contra pessoas não heterossexuais (Guerra, Scarpati, Duarte, Silva, \& Mota, 2014).

Em função disso, considerando as consequências do preconceito frente a minorias sexuais, nos últimos anos pesquisadores têm realizado esforços para estudá-lo, o que demanda contar com instrumentos que $\mathrm{o}$ avaliem. Por se tratar de um fenômeno de interesse em diversos países, procurou-se identificar se havia qualquer medida a respeito nos contextos nacional e internacional. No caso, realizaram-se buscas nas bases Index Psi, PubMed, Scielo, LILACS e Google Acadêmico, utilizando os descritores "preconceito sexual" ("sexual prejudice") e "escala" ("scale"). Como resultado, encontraram-se alguns instrumentos.

No contexto internacional, Hill e Willoughby (2005) desenvolveram a Escala de Transfobia e Diversidade de Identidade de Gênero, formada por 32 itens, avaliando o preconceito e discriminação frente a pessoas "trans" (transexuais, travestis e transgêneros). Nagoshi et al. (2008) propuseram a Escala de Transfobia, composta por 12 itens, que avalia o preconceito contra pessoas transexuais. Costa et al. (2014) desenvolveram a Escala de Atitudes frente aos Direitos Civis de Gays e Lésbicas, formada por onze itens que avaliam atitudes frente a adoção por pessoas do mesmo sexo. A Escala Moderna de Homonegatividade, elaborada por Morrison e Morrison (2002), com 24 itens que focam na avaliação do preconceito moderno frente a gays e lésbicas. Por fim, encontrou-se a Escala Multidimensional do Preconceito Sexual, proposta por Massey (2009), estando formada por 70 itens que avaliam o preconceito sexual a partir do heteresexismo tradicional, a negação contínua da discriminação, a aversão frente a gays e lésbicas, a valorização da causa gay, a resistência à heteronormatividade e as crenças positivas frente a gays e lésbicas.

Em contexto brasileiro, Marinho, Marques, Almeida, Menezes e Guerra (2004) adaptaram uma medida de homofobia. Tal instrumento, formado por 17 itens, mensura o preconceito frente a homossexuais. Gouveia et al. (2011) também adaptaram uma medida ao contexto brasileiro: Escala de Motivações para Responder sem Preconceito frente a Homossexuais, considerando versões relativas a dois grupos minoritários-alvo: gays e lésbicas.
Este instrumento é composto por dez itens equitativamente distribuídos em dois fatores: motivação externa e motivação interna.

Em resumo, como base no resultado desta busca, parece evidente o interesse da comunidade científica acerca da temática do preconceito sexual, realizando estudos a fim de desenvolver instrumentos psicometricamente adequados para avaliá-lo. Não obstante, destaca-se que entre as medidas previamente apresentadas, a proposta por Massey (2009) parece mais coerente com a concepção multidimensional do preconceito sexual. Neste sentindo, decidiu-se adaptá-la ao contexto brasileiro, reunindo evidências de sua validade fatorial e consistência interna, procurando-se descrevê-la sumariamente a seguir.

\section{Escala Multidimensional do Preconceito Sexual (EMPS)}

Elaborada por Massey (2009) no contexto estadunidense, a Multidimensional Measure of Sexual Prejudice (MMSP) deriva seus itens de dois instrumentos prévios sobre preconceito sexual desenvolvido pelo autor: a Modern Heterosexism Scale (MHS) e a Queerl Liberationist Scale (QLS).

Para construção da MHS, inicialmente, reuniram-se 79 itens, procurando conhecer seus parâmetros; por meio de uma análise fatorial exploratória, utilizando extração de máxima verossimilhança (rotação Promax), foram observados três fatores que explicaram $58,9 \%$ da variância total. O primeiro deles, inicialmente descrito como condenação moral, foi composto por 39 itens (por exemplo, A homossexualidade feminina é um pecado); o segundo, nomeado de aversão, reuniu 29 itens (por exemplo, Seria perturbador para mim ficar sozinho com um homem gay); e o terceiro, chamado de negação de discriminação continuada, agrupou 10 itens (por exemplo, Em média, as pessoas em nossa sociedade tratam as pessoas homossexuais e heterossexuais igualmente). As correlações entre os três fatores foram significativas $(\mathrm{p}<0,05)$ e variaram entre 0,38 e 0,68 .

No caso da QLS, Massey (2009) construiu uma versão inicial formada por 73 itens. Estes foram aplicados aos mesmos participantes que responderam a MHS, empregando-se procedimento estatístico semelhante. Como resultado, identificou-se uma estrutura trifatorial que explicou $49,8 \%$ da variância total; o primeiro fator foi denominado de valores progressista dos gays, sendo composto por 32 itens (por 
exemplo, Eu vejo o movimento lésbico e gay como uma coisa importante); o segundo foi definido como resistência à heteronormatividade, estando formado por 12 itens (por exemplo, Eu me sinto restrito pelo rótulo de gênero que as pessoas atribuem a mim); e, o terceiro foi nomeado de crenças positivas, reunindo 11 itens (por exemplo, As lésbicas têm muito a ensinar para outras mulheres sobre serem independentes). As correlações entre os fatores variaram de 0,41 a 0,47 .

Os itens das duas medidas (MHS e QLS) foram posteriormente agrupados (Massey, 2009), compondo a versão de 70 itens da $M M S P$. Esse instrumento foi aplicado a 592 estudantes de graduação com idades entre 17 e 47 anos (61\% mulheres). Uma análise fatorial confirmatória (AFC) com parcela de itens foi conduzida, distribuindo tais itens em sete fatores: traditional heterosexism (heterosexismo tradicional), denial of continued discrimination (negação contínua da discriminação), aversion toward gay men (aversão frente a gays), aversion toward lesbians (aversão frente a lésbicas), valorization of the progress of the gay cause (valorização do progresso da causa gay), resist heteronormativity (resistência à heteronormatividade) e positive beliefs (crenças positivas). Os resultados indicaram um ajuste adequado do modelo proposto (por exemplo, Comparative Fit Index - CFI = 0,99, Tucke$r$-Lewis Index - TLI = 0,99 e Root Mean Square Error Approximation-RMSEA $=0,05$ ).

A partir das evidências psicométricas da Escala Multidimensional de Preconceito Sexual (EMPS), pesquisadores começaram a avaliar sua estrutura fatorial em outros contextos. Barrientos et al. (2015), por exemplo, avaliaram em amostra de 422 estudantes universitários chilenos, chegando a solução tetrafatorial: valorização do progresso de gays e lésbicas $(\alpha=0,88)$, crenças positivas sobre gays $(\alpha=0,83)$, crenças positivas sobre lésbicas ( $\alpha$ $=0,86$ ) e resistência às expectativas heteronormativas $(\alpha=0,80)$. Na mesma direção, Badenes-Ribera, Frias-Navarro, Monterde-i-Bort e Pascual-Soler (2016) verificaram a qualidade psicométrica desta medida em amostra de 417 estudantes de Psicologia da população espanhola, identificando uma estrutura formada por quatro fatores (crenças positivas sobre homens gays, resistência as expectativas heteronormativas, crenças positivas sobre lésbicas e valorização do progresso de gays e lésbicas) cujos alfas de Crobanch variaram de 0,76 a 0,80.
Diante das evidências de estrutura multifatorial e indicadores de consistência interna adequados em diferentes países, a EMPS (Massey, 2009) tem sido utilizada para conhecer os correlatos do preconceito sexual, relacionando-se com diversos construtos, como preconceito moderno (Massey, Merriwether, \& Justin, 2013), preconceito frente a gênero e diversidade sexual (Costa, Peroni, Camargo, Pasley, \& Nardi, 2015), atitudes frente à homoparentalidade e conjugalidade homossexual (Freires, 2015). Nesta direção, parece adequado descrever seu processo de adaptação ao contexto brasileiro, mostrando evidências psicométricas de sua adequação. Estes foram, precisamente, os objetivos que motivaram o presente artigo, que apresenta dois estudos em que se explora sua estrutura fatorial e consistência interna (Estudo 1), comprovando-se posteriormente essa estrutura prévia por meio de análise fatorial confirmatória com parcela de itens (Estudo 2).

\section{Estudo 1. Escala Multidimensional do Preconceito Sexual: Evidências Psicométricas Preliminares}

\section{Método}

\section{Participantes}

Contou-se com amostra de conveniência (não-probabilística) formada por 223 estudantes universitários. Estes tinham idades variando entre 18 e 51 anos $(\mathrm{M}=22,5, \mathrm{DP}=4,42)$, sendo a maioria do sexo feminino $(62,8 \%)$, heterossexual $(67,3 \%)$ e católica (39\%) ou agnóstico $(16,6 \%)$.

\section{Instrumentos}

Os participantes responderam a perguntas demográficas (escolaridade, sexo, idade, orientação sexual e religião), além da EMPS. Descreveu-se previamente a elaboração desta medida e seus parâmetros psicométricos em outros países; considera-se nesta oportunidade a versão composta por 70 itens (por exemplo, Se um homem tem sentimentos homossexuais, ele deveria fazer tudo que puder para superá-los; A ideia do casamento homossexual parece ridícula para mim), os quais são respondidos em escala de sete pontos, variando de $1=$ Discordo totalmente a $7=$ Concordo totalmente. Massey (2009) não apresentou os coeficientes de consistên- 
cia interna de seus presumíveis sete fatores, embora indique que estes foram satisfatórios.

Os processos de tradução e adaptação da EMPS foram realizados conforme as diretrizes da International Test Commission (International Test Commission [ITC], 2017), recentemente padronizadas em língua portuguesa (Borsa, Damásio, \& Bandeira, 2012). Por meio de procedimento de back translation, a escala foi traduzida do inglês para o português por dois psicólogos bilíngues e, em seguida, retraduzida do português para o inglês por outros dois psicólogos bilíngues; observada a compatibilidade do conteúdo das traduções, chegou-se à versão final em português. Como recomendado, esta foi submetida à validação semântica (Pasquali, 2012), contando-se com a participação de 20 estudantes de Psicologia do primeiro período, de ambos os sexos; comprovando-se a adequação das instruções, dos itens e do formato da escala de resposta. A partir desta avaliação qualitativa dos itens, realizaram-se modificações menores, chegando à versão adaptada da medida, que poderá ser solicitada aos autores deste artigo.

\section{Procedimento}

Os dados foram coletados online. Solicitou-se a participação das pessoas por meio de redes sociais e e-mail, garantindo-se o caráter anônimo e a natureza voluntária da participação, assegurando o direito de desistir do estudo sem quaisquer consequências para os participantes. Todos assinaram o Termo de Consentimento Livre e Esclarecido, segundo recomendação da Resolução do Conselho Nacional de Saúde (CNS) $n^{\circ} 466 / 2012$, autorizando a utilização dos dados em produções acadêmico-cientificas. Este estudo contou com aprovação do Comitê de Ética em Pesquisa (CAAE:30598714.1.0000.5302).

\section{Análise de dados}

A análise dos dados foi realizada com o programa $R$ ( $R$ Development Core Team, 2015). Calcularam-se estatísticas descritivas, para caracterizar os participantes do estudo, e análise de componentes principais (ACP), para identificar a estrutura fatorial da medida. Neste caso, avaliou-se a adequação dos dados para realização da ACP por meio do teste de Kaiser-Meyer-Olkin (KMO) e do teste de esfericidade de Bartlett. Por fim, a fim de conhecer a consistência interna dos fatores da escala, calcularam-se alfas de Cronbach.

\section{Resultados}

Inicialmente, verificou-se a adequação de se efetuar uma análise fatorial, observando-se resultados que a apoiaram $[\mathrm{KMO}=0,93 \mathrm{e}$ Teste de esfericidade de Bartlett, $\left.\chi^{2}(2415)=14.479,27, \mathrm{p}<0,001\right]$. Deste modo, com o fim de conhecer o número possível de fatores da EMPS no contexto brasileiro, levaram-se em conta os critérios de Kaiser (valor próprio igual ou superior a 1), Catttell (distribuição gráfica dos valores próprios, desprezando aqueles a partir da configuração do "cotovelo") e Horn (preponderância de valores próprios observados em relação aos simulados).

O critério de Kaiser superestimou o número de componentes da medida, pois até seis poderiam ser extraídos. No entanto, o critério de Cattell sugeriu uma estrutura com cinco componentes. Ambas estruturas não reproduzem exatamente o modelo proposto por Massey (2009), que sugeriu um modelo heptafatorial. Visando dirimir dúvidas sobre o número de componentes, considerou-se o terceiro critério (Horn, análise paralela), pois é mais robusto. Tomando em conta os parâmetros do banco de dados (223 pessoas e 70 variáveis) e realizando 1.000 simulações, corroborou-se a estrutura com cinco fatores; o sexto produzido aleatoriamente foi superior ao gerado a partir dos dados empíricos. Deste modo, realizou-se uma nova ACP, fixando a extração de cinco componentes (rotação varimax), sendo os resultados apresentados na Tabela.

Os cinco componentes explicaram conjuntamente $57,0 \%$ da variância total. Visando interpretá-los, tiveram-se em conta itens com cargas fatoriais iguais ou superiores a 0,30; o item 13 (As leis que consentem o comportamento lésbico deveriam ser incentivadas) foi descartado por não alcançar a saturação mínima em quaisquer dos fatores. Descreve-se a seguir cada um destes componentes:

Componente I. Reuniu 33 itens cujas saturações variaram de 0,40 a 0,81 ; os itens $4,5,7,8,9,11,12,16$, $25,27,31,41,45,46,47,45,48,49,50,51,52$ e 59 são itens invertidos. Seu valor próprio foi de 17,40 , explicando $25 \%$ da variância total, apresentando consistência interna (alfa de Cronbach) de 0,97; este pode ser denominado como heterossexismo.

Componente II. Reuniu 12 itens, com saturações variando de 0,53 a 0,81 . Seu valor próprio foi de 8,61 , explicando $12 \%$ da variância total; ele apresentou alfa de Cronbach de 0,94, sendo denominado como aversão a homossexuais. 


\section{Tabela}

Estrutura fatorial da Escala Multidimensional de Preconceito Sexual.

\begin{tabular}{|c|c|c|c|c|c|c|c|}
\hline \multirow{2}{*}{ Itens } & \multirow{2}{*}{ Descrição do conteúdo } & \multicolumn{5}{|c|}{ Componente } & \multirow{2}{*}{$h^{2}$} \\
\hline & & $\mathrm{I}$ & II & III & IV & $\mathrm{V}$ & \\
\hline 65 & $\begin{array}{c}\text { Homens gays são mais criativos que } \\
\text { os heterossexuais. }\end{array}$ & 0,08 & $-0,04$ & $0,80^{*}$ & 0,07 & 0,03 & 0,65 \\
\hline 67 & As lésbicas têm muito o que ensinar a outras... & 0,09 & $-0,04$ & $0,78^{*}$ & 0,18 & $-0,09$ & 0,67 \\
\hline 66 & Ser lésbica pode fazer uma mulher mais... & 0,01 & $-0,01$ & $0,74^{*}$ & 0,20 & $-0,03$ & 0,60 \\
\hline 63 & Ser gay pode fazer um homem mais compassivo.. & 0,11 & $-0,04$ & $0,74^{*}$ & 0,06 & 0,08 & 0,58 \\
\hline 70 & Penso que as lésbicas são mais disponíveis... & 0,02 & 0,08 & $0,72^{*}$ & $-0,04$ & $-0,11$ & 0,55 \\
\hline 03 & $\begin{array}{c}\text { O comportamento homossexual entre } \\
\text { dois homens é... }\end{array}$ & $-0,81^{*}$ & 0,26 & $-0,09$ & $-0,09$ & $-0,09$ & 0,78 \\
\hline 10 & $\begin{array}{l}\text { A ideia de um casamento homossexual } \\
\text { masculino me... }\end{array}$ & $-0,81^{*}$ & 0,25 & $-0,10$ & $-0,10$ & $-0,20$ & 0,79 \\
\hline 09 & É importante que gays e lésbicas sigam seus... & $0,81^{*}$ & $-0,22$ & 0,14 & $-0,11$ & $-0,13$ & 0,76 \\
\hline 04 & Se duas pessoas realmente se amam, então não... & $0,80^{*}$ & $-0,18$ & 0,17 & 0,10 & $-0,23$ & 0,77 \\
\hline 47 & $\begin{array}{c}\text { Vejo o movimento gay e lésbico como } \\
\text { algo positivo... }\end{array}$ & $0,77^{*}$ & $-0,27$ & 0,29 & 0,24 & $-0,14$ & 0,74 \\
\hline 46 & Se meu filho dissesse que talvez seja gay, eu a... & $0,77^{*}$ & -017 & $-0,09$ & 0,21 & $-0,14$ & 0,69 \\
\hline 45 & Se minha filha dissesse que talvez seja lésbica, eu a... & $0,76^{*}$ & $-0,17$ & 0,10 & 0,20 & $-0,15$ & 0,69 \\
\hline 02 & $\begin{array}{l}\text { A Homossexualidade é um modo de vida } \\
\text { tão moral. }\end{array}$ & $0,77^{*}$ & $-0,22$ & 0,05 & 0,15 & $-0,15$ & 0,68 \\
\hline 01 & A homossexualidade feminina é um pecado... & $-0,76^{*}$ & 0,28 & $-0,05$ & $-0,12$ & 0,10 & 0,68 \\
\hline 16 & Casais homossexuais masculinos deveriam ser ... & $0,75^{*}$ & $-0,22$ & 0,20 & 0,19 & $-0,22$ & 0,73 \\
\hline 06 & $\begin{array}{c}\text { O aumento crescente do número de lésbicas } \\
\text { indica... }\end{array}$ & $-0,75^{*}$ & 0,25 & $-0,01$ & $-0,17$ & 0,20 & 0,69 \\
\hline 08 & Se um homem tem sentimentos homossexuais, ele... & $-0,75^{*}$ & 0,26 & $-0,04$ & $-0,16$ & 0,32 & 0,75 \\
\hline 15 & A homossexualidade feminina é prejudicial para... & $-0,74^{*}$ & 0,35 & $-0,08$ & $-0,11$ & 0,27 & 0,76 \\
\hline 17 & A homossexualidade feminina é uma ameaça a... & $-0,74^{*}$ & 0,42 & $-0,06$ & $-0,14$ & 0,19 & 0,77 \\
\hline 48 & A conquista de direitos civis de gays e lésbicas é... & $0,73^{*}$ & $-0,28$ & 0,13 & 0,15 & $-0,24$ & 0,69 \\
\hline 51 & Os avanços realizados pelo movimento dos... & $0,72^{*}$ & $-0,19$ & 0,13 & 0,20 & $-0,15$ & 0,63 \\
\hline 05 & A homossexualidade masculina é uma perversão... & $-0,72^{*}$ & 0,35 & $-0,05$ & $-0,12$ & 0,23 & 0,70 \\
\hline 49 & $\begin{array}{c}\text { A sociedade é aprimorada pela } \\
\text { diversidade oferecida... }\end{array}$ & $0,71^{*}$ & $-0,19$ & 0,13 & 0,24 & $-0,12$ & 0,63 \\
\hline 12 & $\begin{array}{c}\text { Assim como em outras espécies, } \\
\text { a homossexualidade... }\end{array}$ & $0,70^{*}$ & $-0,14$ & 0,15 & 0,16 & $-0,11$ & 0,56 \\
\hline 52 & Eu admiro a força demonstrada pelas lésbicas... & $0,67^{*}$ & $-0,31$ & 0,26 & 0,18 & $-0,08$ & 0,64 \\
\hline 38 & Gostaria que as lésbicas agissem de forma mais... & $-0,65^{*}$ & 0,34 & 0,05 & $-0,13$ & $-0,04$ & 0,55 \\
\hline 36 & Gostaria que os gays agissem de forma mais... & $-0,63^{*}$ & 0,30 & 0,09 & $-0,07$ & $-0,01$ & 0,49 \\
\hline 42 & Sinto-me desconfortável quando lésbicas agem de... & $-0,61^{*}$ & 0,37 & 0,02 & $-0,09$ & $-0,03$ & 0,51 \\
\hline 50 & Gays e lésbicas devem ser admirados por viverem... & $0,61^{*}$ & $-0,25$ & 0,29 & 0,17 & $-0,12$ & 0,55 \\
\hline 19 & $\begin{array}{c}\text { A homossexualidade feminina é uma } \\
\text { forma inferior... }\end{array}$ & $-0,55^{*}$ & 0,54 & $-0,07$ & $-0,10$ & 0,28 & 0,69 \\
\hline 33 & Sinto-me desconfortável quando gays agem de... & $-0,55^{*}$ & 0,36 & 0,01 & $-0,05$ & $-0,01$ & 0,43 \\
\hline
\end{tabular}




\begin{tabular}{|c|c|c|c|c|c|c|c|}
\hline 07 & A homossexualidade feminina é simplesmente um... & $0,55^{*}$ & $-0,22$ & 0,16 & 0,08 & $-0,29$ & 0,46 \\
\hline 31 & Gostaria de ter mais amigos gays. & $0,48^{*}$ & $-0,33$ & 0,23 & 0,14 & 0,17 & 0,44 \\
\hline 41 & Gostaria de ter mais amigas lésbicas. & $0,48^{*}$ & $-0,19$ & 0,22 & 0,06 & 0,14 & 0,33 \\
\hline 25 & É fácil entender a revolta de grupos de gays e... & $0,46^{*}$ & $-0,36$ & 0,09 & 0,16 & $-0,20$ & 0,41 \\
\hline 59 & $\begin{array}{l}\text { Parece-me que os rótulos “homem” e } \\
\text { "mulher" não... }\end{array}$ & $0,44^{*}$ & $-0,10$ & 0,21 & 0,36 & $-0,05$ & 0,37 \\
\hline 27 & É fácil entender por que os grupos que defendem... & $0,41^{*}$ & $-0,25$ & $-0,01$ & 0,06 & $-0,39$ & 0,38 \\
\hline 11 & A homossexualidade feminina por si só não é um... & $0,40^{*}$ & $-0,03$ & 0,25 & $-0,02$ & $-0,36$ & 0,35 \\
\hline 40 & $\begin{array}{l}\text { Ficaria chateada se descobrisse que } \\
\text { fiquei sozinho(a)... }\end{array}$ & $-0,29$ & $0,81^{*}$ & $-0,02$ & $-0,02$ & 0,07 & 0,76 \\
\hline 29 & Eu tentaria evitar contato com um gay. & $-0,26$ & $0,79^{*}$ & $-0,04$ & $-0,02$ & 0,02 & 0,71 \\
\hline 30 & $\begin{array}{c}\text { Ficaria chateado se descobrisse que } \\
\text { fiquei sozinho... }\end{array}$ & $-0,14$ & $0,76^{*}$ & $-0,00$ & 0,01 & 0,07 & 0,61 \\
\hline 39 & Tento evitar contato com lésbicas. & $-0,35$ & $0,76^{*}$ & $-0,03$ & $-0,03$ & 0,08 & 0,72 \\
\hline 37 & Lésbicas não são mulheres de verdade. & $-0,33$ & $0,74^{*}$ & $-0,10$ & $-0,07$ & 0,08 & 0,70 \\
\hline 35 & Gays não podem ter comportamentos masculinos. & $-0,29$ & $0,74^{*}$ & $-0,04$ & $-0,08$ & 0,16 & 0,67 \\
\hline 34 & Penso que homossexuais masculinos são nojentos. & $-0,44$ & $0,66^{*}$ & $-0,06$ & $-0,11$ & 0,18 & 0,69 \\
\hline 44 & $\begin{array}{l}\text { Lésbicas não podem ter comportamentos } \\
\text { femininos. }\end{array}$ & $-0,33$ & $0,65^{*}$ & 0,04 & 0,00 & 0,17 & 0,55 \\
\hline 43 & Penso que homossexuais femininas são nojentas. & $-0,46$ & $0,63^{*}$ & $-0,07$ & $-0,08$ & 0,15 & 0,64 \\
\hline 32 & Gays não são homens de verdade. & $-0,37$ & $0,62^{*}$ & 0,00 & $-0,20$ & 0,06 & 0,56 \\
\hline 14 & Lésbicas são doentes. & $-0,45$ & $0,57^{*}$ & $-0,03$ & 0,00 & 0,17 & 0,55 \\
\hline 18 & Homossexuais masculinos não deveriam ter... & $-0,34$ & $0,53^{*}$ & $-0,09$ & 0,04 & 0,13 & 0,42 \\
\hline 61 & Os homens gays são mais disponíveis... & 0,01 & 0,04 & $0,71^{*}$ & $-0,01$ & 0,01 & 0,50 \\
\hline 64 & Homens heterossexuais tem muito que aprender ... & 0,13 & $-0,07$ & $0,69^{*}$ & 0,08 & $-0,00$ & 0,51 \\
\hline 62 & Homens heterossexuais tem muito que aprender... & 0,27 & $-0,08$ & $0,69^{*}$ & 0,01 & $-0,03$ & 0,56 \\
\hline 69 & Lésbicas têm estado mais à frente na luta pelos... & 0,04 & $-0,09$ & $0,56^{*}$ & 0,11 & $-0,08$ & 0,34 \\
\hline 68 & $\begin{array}{l}\text { A situação de lésbicas e gays só vai } \\
\text { melhorar quando... }\end{array}$ & 0,33 & $-0,07$ & $0,38^{*}$ & 0,23 & $-0,13$ & 0,32 \\
\hline 55 & $\begin{array}{l}\text { Sinto-me limitado pelos comportamentos } \\
\text { sexuais que... }\end{array}$ & 0,26 & $-0,05$ & 0,10 & $0,88^{*}$ & $-0,12$ & 0,87 \\
\hline 54 & $\begin{array}{l}\text { Sinto-me limitado pelo rótulo sexual que as } \\
\text { pessoas... }\end{array}$ & 0,24 & $-0,08$ & 0,14 & $0,87^{*}$ & $-0,04$ & 0,86 \\
\hline 53 & Sinto-me limitado pelo rotulo de gênero que as... & 0,21 & $-0,06$ & 0,18 & $0,83^{*}$ & $-0,01$ & 0,79 \\
\hline 57 & $\begin{array}{c}\text { Sinto-me limitado pelas expectativas que as } \\
\text { pessoas... }\end{array}$ & 0,30 & $-0,06$ & 0,03 & $0,83^{*}$ & $-0,17$ & 0,82 \\
\hline 56 & $\begin{array}{l}\text { Sinto-me limitado pelas regras e normas } \\
\text { sexuais da... }\end{array}$ & 0,35 & $-0,08$ & 0,11 & $0,79^{*}$ & $-0,13$ & 0,79 \\
\hline 58 & Preocupo-me quanto a privilégios que recebo da... & 0,06 & $-0,00$ & 0,14 & $0,55^{*}$ & $-0,19$ & 0,36 \\
\hline 60 & $\begin{array}{c}\text { Acredito que a maioria das pessoas e } \\
\text { basicamente... }\end{array}$ & 0,32 & $-0,02$ & 0,38 & $0,40^{*}$ & $-0,02$ & 0,42 \\
\hline 20 & Em média, as pessoas da nossa sociedade tratam os... & $-0,02$ & 0,07 & $-0,08$ & $-0,05$ & $0,73^{*}$ & 0,55 \\
\hline 22 & A sociedade alcançou o ponto onde gays e... & $-0,03$ & 0,12 & 0,03 & $-0,09$ & $0,71^{*}$ & 0,53 \\
\hline 21 & A maioria das lésbicas e gays não sofrem mais de... & $-0,20$ & 0,12 & $-0,13$ & $-0,00$ & $0,69^{*}$ & 0,55 \\
\hline
\end{tabular}




\begin{tabular}{lccccccc}
\hline 24 & $\begin{array}{c}\text { Discriminação contra gays e lésbicas não é } \\
\text { mais um... }\end{array}$ & $-0,22$ & 0,22 & 0,00 & $-0,02$ & $0,58^{*}$ & 0,44 \\
23 & É raro ver gays e lésbicas sendo tratados de forma... & $-0,20$ & 0,20 & 0,13 & $-0,10$ & $0,51^{*}$ & 0,38 \\
26 & Lésbicas e gays muitas vezes perdem bons empregos... & 0,19 & 0,01 & 0,01 & 0,12 & $-0,35^{*}$ & 0,18 \\
28 & Muitas lésbicas e gays ainda perdem o emprego... & 0,24 & $-0,07$ & 0,01 & 0,21 & $-0,35^{*}$ & 0,23 \\
$13 \quad$ As leis que consentem o comportamento lésbico... & 0,03 & 0,00 & 0,15 & 0,07 & $-0,19$ & 0,06 \\
Número de itens & 33 & 12 & 10 & 7 & 7 & \\
Valor próprio & 17,4 & 8,61 & 5,83 & 5,19 & 4,02 & \\
Alfa de Cronbach & 0,97 & 0,94 & 0,89 & 0,91 & 0,75 & \\
$\%$ Variância total & $25 \%$ & $12 \%$ & $8 \%$ & $7 \%$ & $5 \%$ & \\
\hline
\end{tabular}

* Itens retidos no respectivo componente; $\mathrm{h}^{2}=$ comunalidade; componente $\mathrm{I}=$ heterossexismo, componente II = aversão a homossexuai, componente III = crenças positivas frente a homossexuais, componente IV = resistência à heteronormatividade, componente $\mathrm{V}$ = negação da discriminação.

Componente III. Reuniu 10 itens cujas saturações variaram de 0,38 a 0,80 . Seu valor próprio foi de 5,83, explicando $8 \%$ da variância total, tendo consistência interna (alfa de Cronbach) de 0,89; segundo o conteúdo de seus itens, pode-se nomeá-lo como crenças positivas frente a homossexuais.

Componente IV. Reuniu sete itens com saturações variando de 0,40 a 0,88 . Seu valor próprio foi de 5,19, explicando $7 \%$ da variância total. Seu alfa de Cronbach foi de 0,91 , sendo denominado como resistência à heteronormatividade.

Componente V. Reuniu sete itens cujas saturações variaram entre -0,35 e 0,73. Ressalta-se que os itens 26 e 28 são invertidos. Seu valor próprio foi de 4,02 , explicando $5 \%$ da variância total, tendo apresentado alfa de Cronbach de 0,49; decidiu-se denominá-lo como negação da discriminação.

Em resumo, a estrutura observada desta medida no Brasil foi pentafatorial. Embora com dois fatores a menos que os observados no estudo de sua elaboração, os fatores foram na direção do que têm sido observado. Resta, entretanto, testar se a estrutura pentafatorial pode ser replicada em estudo independente.

\section{Estudo 2. Estrutura Fatorial e Testagem de Modelos Reduzidos da EMPS}

\section{Método}

\section{Participantes, instrumentos e procedimento}

Contou-se com uma amostra de conveniência (não probabilística) de 261 pessoas da população geral, tendo idades variando de 18 a 58 anos $(M=30,0$, $\mathrm{DP}=9,35)$, a maioria do sexo feminino $(61,7 \%)$, heterossexual $(72,8 \%)$, católica $(41,8 \%)$ ou evangélica $(13,7 \%)$. Estas responderam aos mesmos instrumentos do Estudo 1, seguindo-se procedimento similar; o estudo foi realizado no marco do projeto aprovado pelo Comitê de Ética em Pesquisa com Seres Humanos, previamente citado.

\section{Análise de dados}

Utilizou- se o programa $R$ ( $R$ Development Core Team, 2015) para analisar os dados e a AFC, adotando-se o estimador Robust Maximum Likelihood (MLR). Os seguintes indicadores de ajuste foram considerados (Brown, 2015; Tabachnick, \& Fidell, 2013): (a) razão qui-quadrado por graus de liberdade $\left(\chi^{2} / g l\right)$, admitindo como recomendáveis valores entre 2 e 3 , aceitando-se até 5; (b) CFI e TLI, aceitando-se valores iguais ou superiores a 0,90, (c) Standardized Root Mean Square Residual (SRMR), admitindo-se como ajustado modelo com valor abaixo de 0,08, e RMSEA, cujos valores recomendados se situam entre 0,05 e 0,08, admitindo-se até 0,10 .

\section{Resultados}

Inicialmente, apresentam-se os resultados referentes ao modelo original da EMPS, isto é, a solução heptafatorial proposta por Massey (2009). Tais resultados se referirão à confirmação da estrutura fatorial por meio da técnica de parcelamento de itens. Em um segundo momento, serão apresentados os resultados relacionados ao modelo alternativo pen- 
tafatorial, que foi observado no contexto brasileiro (Estudo 1), adotando-se a mesma técnica. Esta decisão decorreu do número de participantes do estudo $(n=261)$ ser inferior à recomendação de dez partícipes por variável (Pasquali, 2012). Trata-se de combinar variáveis calculando a média dos itens por parcela, visando chegar a um conjunto menos complexo de indicadores (variáveis) (Hair, Black, Babin, Anderson, \& Tatham, 2009).

A partir da estrutura fatorial da EMPS proposta por Massey (2009), criaram-se as parcelas de itens. Em termos práticos, isso significa que novas variáveis foram criadas no banco de dados, consistindo à média de itens correspondentes a cada um dos sete fatores desse autor. O parcelamento de itens foi realizado por meio da estratégia empírica, agrupando os itens pela aproximação da covariância destes (Hair et al., 2009). As parcelas foram formadas a partir do escore fatorial dos itens de cada fator da EMPS original, fixando-se a extração em três componentes por conjunto de itens de cada um dos sete fatores. Em seguida, calculou-se a AFC com as parcelas representando cada uma de suas dimensões. As saturações dos seus itens foram como seguem: heterossexismo sexual $(0,77,-0,55 \mathrm{e}$ $0,67)$, negação da discriminação contínua $(0,89,0,54$ e - 0,35$)$, aversão frente a gays $(0,84,0,83$ e 0,86$)$, aversão frente a lésbicas $(0,91,0,53$ e 0,77$)$, valores progressistas gays $(0,88,0,94$ e 0,89$)$, resistência à heteronormatividade $(0,93,0,90$ e 0,60$)$ e crenças positivas $(0,83,0,85$ e 0,85$)$.

Posteriormente, ainda tendo em conta a técnica de parcela de itens, testou-se a estrutura pentafatorial da EMPS (Estudo 1). Com o intuito de propor uma medida parcimoniosa, selecionaram-se os sete itens com maior carga fatorial em cada um dos cinco fatores, compondo uma versão reduzida da EMPS. Utilizaram-se os procedimentos para montagem das parcelas de itens citados anteriormente, cujos valores das saturações foram: heterossexismo $(0,85$ e 0,54$)$, aversão a gays e lésbicas $(0,71$ e - 0,26$)$, crenças positivas frente a gays e lésbicas $(0,34$ e 0,73$)$, resistência à heteronormatividade $(0,62$ e -0,65) e negação da discriminação $(0,39$ e 0,90$)$.

Quanto aos índices de ajustes destes dois modelos confirmatórios, observou-se superioridade daquele com cinco fatores quando comparado ao de sete, conforme os indicadores: modelo heptafatorial: $\chi^{2}(168)=580,34, \chi^{2} / g l=3,45$, CFI $=0,89$, TLI $=0,86$, SRMR $=0,11$ e RMSEA $=0,097($ IC90\% $=0,088-0,106)$; e modelo pentafatorial: $\chi^{2}(25)=60,02, \chi^{2} / g l=2,40$, $\mathrm{CFI}=0,93, \mathrm{TLI}=0,89, \mathrm{SRMR}=0,05$ e RMSEA $=0,062$ $($ IC90\% $=0,039-0,085)$. De fato, quando ambos foram comparados, o modelo pentafatorial se mostrou estatisticamente mais adequado $\left[\Delta \chi^{2}(143)=487,65\right.$, $\mathrm{p}<0,001]$. Por fim, destaca-se que os pesos fatoriais (lambdas) foram estatisticamente diferentes de zero $(\lambda \neq 0 ; t>1,96, \mathrm{p}<0,05)$ em ambos os modelos.

A partir dos resultados expostos, chegou-se a versão reduzida da EMPS, composta por 35 itens, com cinco fatores, sendo sete itens por fator e reunindo evidências de consistência interna (alfa de Cronbach, $\alpha)$ satisfatórias para cada um deles: heterossexismo $(\alpha=0,82)$, aversão a gays e lésbicas $(\alpha=0,88)$, crenças positivas frente a gays e lésbicas $(\alpha=0,88)$, resistência à heteronormatividade $(\alpha=0,89)$ e negação da discriminação $(\alpha=0,76)$.

\section{Discussão}

De acordo com Massey (2009), o preconceito frente aos homossexuais se apresenta de forma diferenciada de outros tipos de preconceitos, possuindo variadas configurações e origens próprias, sendo considerado polimorfo (polymorphous prejudice), descrevendo atitudes negativas das pessoas frente a homossexuais. Esta concepção é utilizada para contemplar ao máximo todas as particularidades do preconceito sexual (por exemplo, ideologias e concepções estruturantes das atitudes frente aos homossexuais). Nesta conjuntura, considerando que a EMPS pode fornecer um entendimento multidimensional do preconceito sexual, este artigo procurou apresentar evidências psicométricas desta medida em contexto brasileiro.

Apesar de o propósito principal ter sido alcançado, algumas limitações dos estudos podem ser pensadas. Inicialmente, destaca-se o fato de as amostras terem sido de conveniência, sendo os participantes recrutados na internet. Portanto, provavelmente não são representativas das populações das quais foram retiradas, o que restringe quaisquer generalizações quanto a magnitude do preconceito das pessoas. Como segunda limitação potencial, a EMPS é uma medida de autorrelato, do tipo "lápis e papel", sendo possível que as pessoas o respondam mostrando um perfil mais socialmente desejável (Soares et al., 2016). Portanto, tomando em conta esses dois vieses potenciais, recomendam-se que em estudos futuros se teste a adequação desta medida em grupos mais represen- 
tativas da população brasileira e se tenha em conta um fator de desejabilidade social; alternativamente, recomenda-se desenvolver medidas implícitas do construto preconceito sexual, procurando contemplar sua natureza multifatorial (Massey, 2009).

Não obstante as limitações potenciais levantadas, os achados dos estudos descritos apoiam a adequação da versão brasileira da EMPS, sobretudo de sua versão reduzida. No Estudo 1 foram considerados critérios múltiplos (Kaiser, Cattell e Horn) que permitiram identificar a solução pentafatorial desta medida, que, embora com menor número de fatores, ainda consegue cobrir o conteúdo das sete dimensões propostas por Massey (2009). Posteriormente, comparou-se o modelo original de sete fatores, confrontando-o com o observado de cinco fatores (Estudo 2). Os resultados apontaram indicadores de ajuste superiores para a solução parcimoniosa de cinco fatores (Tabachnick \& Fidell, 2013). A propósito, a parcimônia de uma escala em Psicologia é um aspecto útil, sobretudo quando se considera que o comportamento humano é multideterminado e pode variar transculturalmente (Borsa et al., 2012).

Quanto às dimensões observadas, o heterossexismo agrupou itens que representam a ideia de que a heterossexualidade é o único padrão sexual considerado aceitável. Costa e Nardi (2015) pontuam que o heterossexismo vai além de preconcepções e julgamentos tendenciosos acerca de homossexuais, mas está relacionado com a manutenção de papéis sociais e reprodução do machismo e sexismo. Em outras palavras, configura-se como um sistema coletivo de disseminação de normas e valores, estruturado a partir das diferenças entre gêneros, que serve para legitimar a concepção de que os homossexuais são "violadores" de normas de gênero, já que sua conduta não corresponde ao que é esperado por indivíduos de seu sexo (Herek, 2015).

A dimensão aversão frente a homossexuais, originalmente distribuído em duas dimensões (aversão frente a gays e aversão frente a lésbicas; Massey, 2009), reuniu itens voltados ao sentimento de repulsa e nojo frente aos homossexuais. Em torno dessa discussão, Herek (2015) vai apontar que existem distintas motivações para as atitudes e os sentimentos negativos direcionados à orientação sexual de uma pessoa, sugerindo que duas das funções do preconceito sexual são expressão de valores e expressão social. A primeira função se refere às crenças morais e valores que um indivíduo possui, sendo suas condutas preconceituosas explicadas por aspectos cognitivos; as crenças negativas frente a gays e lésbicas estariam relacionadas com a manutenção do preconceito sexual (Massey, 2009); a segunda diz respeito às conjunturas nas quais ocorre preconceito sexual, revelando a manifestação de atitudes preconceituosas por parte dos indivíduos no sentido de participar e agir em consonância com seu grupo social.

A dimensão crenças positivas frente a homossexuais reuniu itens que indicam a ideia de que os homossexuais apresentam características positivas em relação aos heterossexuais, tais como níveis maiores de criatividade e autossuficiência. Este reconhecimento é importante; Albernaz e Kauss (2015) chamam a atenção para importância do desenvolvimento de políticas públicas que atuem no sentido de reconhecer e promover, no âmbito das atribuições de cada um de seus membros, os direitos à igualdade e à não-discriminação das pessoas lésbicas, gays, bissexuais, travestis, transexuais e transgêneros, tanto dentro dos serviços públicos em geral quanto na educação, nas relações de emprego e nos meios de comunicação.

A dimensão resistência à heteronormatividade foi constituída por itens que abordam uma atitude negativa em relação aos padrões socialmente estabelecidos de gênero. Tais aspectos podem ser mais bem elucidados pela ampliação trazida a partir das normas sociais de padrão hetero-cis-normativo (ou cisheteronormatividade). Entende-se por cisheteronormatividade todo e qualquer instrumento normativo de papéis de gênero, concebido de maneira essencialista, ou seja, trata-se de normas binárias que referendam a feminilidade/masculinidade a partir de determinantes biológicos. Tais normas incidem na sociedade, produzindo identidades sexuais impedidas de "possibilidades de derivação passível de apropriação pessoal, social, cultural e histórica do feminino e do masculino, por pessoas de ambos os sexos" (Lionço \& Diniz, 2008, p. 310). Nesta linha de pensamento, a resistência à heteronormatividade contempla uma ação negativa frente à institucionalização da heterossexualidade como única norma social vigente (Costa et al., 2014).

Quanto à dimensão negação da discriminação, esta foi formada por itens que enfocam ações não-discriminatórias contra os homossexuais. Apesar da nomenclatura da dimensão em questão, é preciso atentar para o conteúdo de seus itens (por exemplo, 
Em média, as pessoas da nossa sociedade tratam os gays e os heterossexuais igualmente; A discriminação contra gays e lésbicas não é mais um problema no Brasil), que são consoantes com a manifestação sutil do preconceito, em que os indivíduos se manifestam de maneira contrária a discriminação contra homossexuais; contudo, ao mesmo tempo, opõem-se às demandas e reivindicações do grupo que é objeto de preconceito, assumindo uma concepção de que tais exigências são desnecessárias, não havendo assim a necessidade de leis e políticas públicas que apoiem a proteção de tal grupo (Cerqueira-Santos et al., 2017). Neste âmbito, é recorrente pensar que o preconceito frente a grupos minoritários tenha diminuído ao longo do tempo, devido a aspectos relacionados à transformação do contexto social, político e histórico. Destarte, constata-se que o mesmo segue existindo, porém sob uma forma de expressão mais sutil e implícita (Gouveia et al., 2011).

É importante reconhecer que foram dados os primeiros passos para adaptar a EMPS no contexto brasileiro. Não obstante, demandam-se novos estudos. Por exemplo, os estudos ora descritos focaram na consistência interna como indicador de confiabilidade, mas poderá ser promissor checar evidências de estabilidade temporal (teste-reteste) desta medida. Poderá ser igualmente importante conhecer evidências de sua validade convergente com outras medidas de preconceito, como a escala de motivações para responder sem preconceito frente a gays e lésbicas (Gouveia et al., 2011) ou a escala de homofobia (Marinho et al., 2004). Certamente, valerá a pena conhecer os correlatos do preconceito sexual; talvez construtos como valores, traços de personalidade e orientação à dominância possam arrojar luz à temá- tica, mas caberia especular, no âmbito deste país, se um construto mais antropológico, como o "jeitinho brasileiro", poderia ser uma atenuante ou agravante deste preconceito.

Por fim, as dimensões da EMPS identificadas no contexto brasileiro reforçam a ideia de que o preconceito sexual é um fenômeno que se apresenta de forma polimorfa, incorporando componentes sociais (culturais e políticos) relacionados ao preconceito e aos estigmas que o compõem, como as ideologias de cunho social. Destaca-se que este preconceito não se restringe a "disposições individuais", sendo um produto de aspectos históricos, políticos e culturais demarcados e influenciados diretamente pelo social, no seu sentido mais amplo, e incorporando os dispositivos sociais "normatizadores", que simbolicamente instituem padrões e condutas relacionais (intra e intergrupais) (Freires, Barbosa, Coelho, Santos, \& Moizéis, 2017). Espera-se contribuir para o preenchimento de uma lacuna na literatura brasileira acerca das controvérsias torno do termo homofobia já apontadas por Nardi e Costa (2015). Fica claro, portanto, que não pretende-se suplantar tal termo, tendo em vista a sua contribuição científica e social. Em termos práticos, o objetivo, em questão é dirimir suas fragilidades, pois, a utilização de tal termo implica na minimização de outras formas de hostilidade (por exemplo, violência, assassinato), criando um contexto social de produção de violência deliberada contra as pessoas não heterossexuais. Considerando tal contexto, nesta oportunidade, investigamos os parâmetros psicométricos da Escala Multidimensional de Preconceito Sexual no contexto brasileiro, colocando-a a disposição dos pesquisadores para que impulsione novos estudos no Brasil a esse respeito.

\section{Referências}

Albernaz, R. O., \& Kauss, B. S. (2015). Reconhecimento, igualdade complexa e luta por direitos à população LGBT através das decisões dos tribunais superiores no Brasil. Revista de Psicologia Política, 15(34), 547-561.

Badenes-Ribera, L., Frias-Navarro, D., Monterde-i-Bort, H., \& Pascual-Soler, M. (2016). Spanish validation of the polymorphous prejudice scale in a sample of university students. Journal of Homosexuality, 63(11), 1517-1536. https://doi.org/10.1080/00918369.2016.1223349

Barrientos, D. J., Cárdenas, M., Estrada, C., Adaos, R., Carvajal, J., Peña, M. et al. (2015). Adaptation and validation of the polymorphous prejudice scale (PPS): A short form in a sample of heterosexual Chilean college students. International Journal of Sexual Health, 27(3), 235-248. https:/ / doi.org/10.1080/ 19317611.2014.957795

Borsa, J. C., Damásio, B. F, \& Bandeira, D. R. (2012). Adaptação e validação de instrumentos psicológicos entre culturas: algumas considerações. Paidéia, 22(53),423-432. https://doi.org/10.1590/1982-43272253201314 
Freires, L. A., Rezende, A. T., Loureto, G. D. L., Santos, W. S., Mendes, L. A. C. \& Gouveia, V. V. (2019). Mensuração do Preconceito Sexual.

Brown, T. A. (2015). Confirmatory factor analysis for applied research. New York, NY: The Guilford.

Cerqueira-Santos, E., Nunes, L. M., \& Silveira, A. P. (2017). Homofobia internalizada e religiosidade entre casais homoafetivos. Temas em Psicologia, 25(2), 691-702. https://doi.org/10.9788/TP2017.2-15

Chandra, A., Copen, C. E., \& Mosher, W. D. (2013). Sexual behavior, sexual attraction, and sexual identity in the United States: Data from the 2006-2010 national survey of family growth. In A. K. Baumle, International handbook on the demography of sexuality (pp. 45-66). Dordrecht: Springer.

Costa, P. A., Almeida, R., Anselmo, C., Ferreira, A., Pereira, H., \& Leal, I. (2014). University students' attitudes toward same-sex parenting and gay and lesbian rights in Portugal. Journal of Homosexuality, 61(12), 1667-1686. https://doi.org/10.1080/00918369.2014.951253

Costa, A. B., Peroni, R. O., Camargo, E. S., Pasley, A., \& Nardi, H. C. (2015). Prejudice toward gender and sexual diversity in a Brazilian Public University: prevalence, awareness, and the effects of education. Sexuality Research and Social Policy, 12(4), 261-272. https://doi.org/10.1007/s13178-015-0191-z

Costa, A. B., \& Nardi, H. C. (2015). Homofobia e preconceito contra diversidade sexual: debate conceitual. Temas em Psicologia, 23(3), 715-726. https://doi.org/10.9788/TP2015.3-15

Freires, L. A. (2015). Atitudes frente a homoparentalidade: Uma explicação a partir de variáveis explícitas e implícitas (tese). Departamento de Psicologia, Universidade Federal da Paraíba, João Pessoa, PB.

Freires, L. A., Barbosa, L.H.G.M., Coelho, G. L. H., Santos, L.C.O, \& Moizeis, H. B. C (2017). O estudo das relações intergrupais no contexto dos grupos minoritários: resgatando perspectivas clássicas e atuais da psicologia social. In C. F. Lima, \& C. E. Pimentel (Orgs.). Revisitando a psicologia social (pp. 94-124). Curitiba, PR: Juruá.

Gouveia, V. V., Souza, L. E. C., Vione, K. C., Cavalcanti, M., F. B., Santos, W. S., \& Medeiros, E. D. (2011). Motivation to respond without prejudice: Evidences of a measure toward gays and lesbians. Psicologia: Reflexão e Crítica, 24(3), 458-466. https://doi.org/10.1590/S0102-79722011000300006

Guerra, V. M., Scarpati, A. S., Duarte, C. N. B., Silva, C. V., \& Motta, T. A. (2014). Ser homem é...: Adaptação da Escala de Concepções da Masculinidade. Psico-USF, 19(1), 155-165. https://doi.org/10.1590/S141382712014000100015

Hair, J. R., Jr., Black, W. C., Babin, B. J., Anderson, R. E., \& Tatham, R. L. (2009). Análise multivariada de dados (6a ed.). Porto Alegre, RS: Bookman.

Herek, G. M. (2000). Sexual prejudice and gender: Do heterosexuals' attitudes toward lesbians and gay men differ?. Journal of Social Issues, 56(2), 251-266. https:// doi.org/10.1111/0022-4537.00164

Herek, G. M. (2015). Beyond "homophobia": Thinking more clearly about stigma, prejudice, and sexual orientation. American Journal of Orthopsychiatry, 85(5 suppl), 29-37. https://doi.org/10.1037/ort0000092

Herek, G. M., \& McLemore, K. A. (2013). Sexual prejudice. Annual Review of Psychology, 64, 309-333. https://doi. org/10.1146/annurev-psych-113011-143826

Hill, D. B., \& Willoughby, B. L. (2005). The development and validation of the genderism and transphobia scale. Sex Roles, 53(7-8), 531-544. https:// doi.org/10.1007/s11199-005-7140-x

International Test Commission - ITC. (2017). ITC Guidelines for translating and adapting tests (2nd ed., version 2.4). Recuperado de https://www.intestcom.org/files/guideline_test_adaptation_2ed.pdf

Lionço, T., \& Diniz, D. (2008). Homofobia, silêncio e naturalização: Por uma narrativa de diversidade sexual. Psicologia Política, 18(16), 307-324.

Marinho, C. A., Marques, E. F. M., Almeida, D. R., Menezes, A. R. B., \& Guerra, V. M. (2004). Adaptação da Escala de Homofobia explícita e implícita ao contexto brasileiro. Paideia, 14(29), 371-379. https://doi.org/10.1590/S0103863X2004000300012

Massey, S. (2009). Polymorphous prejudice: Liberating the measurement of heterosexuals' attitudes toward lesbians and gay men. Journal of Homosexuality, 56(2), 147-172. https://doi.org/10.1080/00918360802623131

Massey, S. G., Merriwether, A. M., \& Garcia, J. R. (2013). Modern prejudice and same-sex parenting: Shifting judgments in positive and negative parenting situations. Journal of GLBT Family Studies, 9(2), 129-151. https:// doi.org/10.1080/1550428X.2013.765257 
Morrison, M. A., \& Morrison, T. G. (2002). Development and validation of a scale measuring modern prejudice toward gay men and lesbian women. Journal of Homosexuality, 43(2), 15-37. https://doi.org/10.1300/J082v43n02_02

Nagoshi, J. L., Adams, K. A., Terrell, H. K., Hill, E. D., Brzuzy, S., \& Nagoshi, C. T. (2008). Gender differences in correlates of homophobia and transphobia. Sex Roles, 59, 521-531. https://doi.org/10.1007/s11199-008-9458-7

Pasquali, L. (2012). Análise fatorial para pesquisadores. Brasília, DF: LabPAM.

R Core Team. (2015). R: A language and environment for statistical computing: Reference index. Recuperado de https://cran.r-project.org/doc/manuals/fullrefman.pdf

Santos, W. S., Gouveia, V. V., Navas, M. S., Pimentel, C. E., \& Gusmão, E. E. S. (2006). Escala de racismo moderno: Adaptação ao contexto brasileiro. Psicologia em Estudo (Maringá), 11(3), 637-645.

Soares, A. K. S., Lopes, G. S., Rezende, A. T., Ribeiro, M. G. C., Santos, W. S., \& Gouveia, V. V. (2016). Escala de desejabilidade social infantil (EDSI): Evidências de validade fatorial e consistência interna. Avances en Psicología Latinoamericana, 34(2), 383-394. https:// doi.org/10.12804/apl34.2.2016.11

Tabachnick, B. G., \& Fidell, L. S. (2013). Using multivariate statistics (6th ed.). Boston, MA: Allyn \& Bacon.

Whitley, B. E., Jr., \& Kite, M. E. (2016). Psychology of prejudice and discrimination. NewYork, NY: Routledge.

\section{Leogildo Alves Freires}

Doutor em Psicologia Social pela Universidade Federal da Paraíba (UFPB). Professor classe A, Nível II (Adjunto A) do Instituto de Psicologia da Universidade Federal de Alagoas (UFAL). Atualmente coordena o Laboratório de Psicometria e Avaliação Psicológica (LAPAP/UFAL).

E-mail: leogildo.freires@ip.ufal.br

(iD) https://orcid.org/0000-0001-5149-2648

\section{Alessandro Teixeira Rezende}

Mestre em Psicologia Social pela Universidade Federal da Paraíba (UFPB). É colaborador do núcleo de Pesquisa Bases Normativas do Comportamento Social (BNCS).

E-mail: alessandro.teixeira.rezende@gmail.com

(iD) https://orcid.org/0000-0002-5381-2155

\section{Gleidson Diego Lopes Loureto}

Mestre em Psicologia Social pela Universidade Federal da Paraíba (UFPB). Professor do curso de Psicologia do Centro Universitário de Patos-PB (UNIFIP). É colaborador do núcleo de Pesquisa Bases Normativas do Comportamento Social (BNCS).

E-mail: diegoloureto.dl@gmail.com

(iD) https://orcid.org/0000-0002-0889-6097

\section{Walberto Silva dos Santos}

Doutor em Psicologia Social pela Universidade Federal da Paraíba (UFPB). Professor Associado da Universidade Federal do Ceará (UFC). Atualmente coordena o Laboratório Cearense de Psicometria (LACEP).

E-mail:walbertosantos@gmail.com

(iD) https://orcid.org/0000-0002-6344-7059

\section{Luis Augusto de Carvalho Mendes}

Doutor em Psicologia Social pela Universidade Federal da Paraíba (UFPB). Professor da Faculdade Maurício de Nassau, PB, Brasil. Atualmente atua nas áreas de Psicologia Clínica, Pesquisa, Marketing, Comportamento do Consumidor e Psicologia Social..

E-mail: luisaugustomendes@gmail.com

(iD) https://orcid.org/0000-0003-3841-9870 


\section{Valdiney Veloso Gouveia}

Doutor em Psicologia Social pela Universidade Complutense de Madrid. Professor titular do Departamento de Psicologia da Universidade Federal da Paraíba e bolsista de produtividade (1A) do CNPq.

E-mail: vvgouveia@gmail.com

(iD) https:// orcid.org/0000-0003-2107-5848

Endereço para envio de correspondência:

Universidade Federal de Alagoas

Instituto de Psicologia, Sala 5. Av. Lourival Melo Mota, S/N, 57072-970 - Campus AC Simões

Recebido 10/09/2019

Aceito 04/10/2019

Received 09/10/2019

Approved 10/04/2019

Recibido 10/09/2019

Aceptado 04/10/2019

Como citar: Freires, L. A., Rezende, A. T., Loureto, G.D.L., Santos, W.S., Mendes, L.A.C., \& Gouveia, V.V. (2019). Escala Multidimensional de Preconceito Sexual: Propriedades Psicométricas para o Contexto Brasileiro. Psicologia: Ciência e Profissão, 39 (n.spe 3), 222-235. https://doi.org/10.1590/1982-3703003228490

How to cite: Freires, L. A., Rezende, A. T., Loureto, G.D.L., Santos, W.S., Mendes, L.A.C., \& Gouveia, V.V. (2019). Multidimensional Scale of Sexual Prejudice: Psychometric Properties for the Brazilian Context. Psicologia: Ciência e Profissão, 39 (n.spe 3), 222-235. https://doi.org/10.1590/1982-3703003228490

Cómo citar: Freires, L. A., Rezende, A. T., Loureto, G.D.L., Santos, W.S., Mendes, L.A.C., \& Gouveia, V.V. (2019). Escala Multidimensional de Prejuicio Sexual (EMPS): Propiedades Psicométricas para el Contexto Brasileño. Psicologia: Ciência e Profissão, 39 (n.spe 3), 222-235. https://doi.org/10.1590/1982-3703003228490 